\title{
Microfluidic Flow through Polyaniline Supported by Lamellar- Structured Graphene for Mass-Transfer-Enhanced Electrocatalytic Reduction of Hexavalent Chromium
}

\author{
Qinghua Ji, ${ }^{\dagger, \dagger}$ Dawei Yu, ${ }^{\dagger, \dagger}$ Gong Zhang, ${ }^{\dagger, \dagger}$ Huachun Lan, ${ }^{\dagger}$ Huijuan Liu, ${ }^{*}{ }^{\dagger}$ and Jiuhui $\mathrm{Qu}^{\dagger}$ \\ ${ }^{\dagger}$ Key Laboratory of Drinking Water Science and Technology, Research Center for Eco-Environmental Sciences, Chinese Academy of \\ Sciences, Beijing 100085, China \\ ${ }^{\ddagger}$ University of Chinese Academy of Sciences, Beijing 100049, China
}

\section{Supporting Information}

\begin{abstract}
Owing to its high efficiency and environmental compatibility, electroreduction holds great promise for the detoxification of aqueous $\mathrm{Cr}(\mathrm{VI})$. However, the typical electroreduction system often shows poor mass transfer, which results in slow reduction kinetics and hence higher energy consumption. Here, we demonstrate a flow-through electrode of polyaniline supported on lamellar-structured graphene (LGS-PANI) for electrocatalytic reduction of $\mathrm{Cr}(\mathrm{VI})$. The reaction kinetics of the LGSPANI flow-through electrodes are 6.4 times (at acidic condition) and 17.3 times (at neutral condition) faster than traditional immersed parallel-plate electrodes. Computational fluid dynamics simulation suggests that the flow-

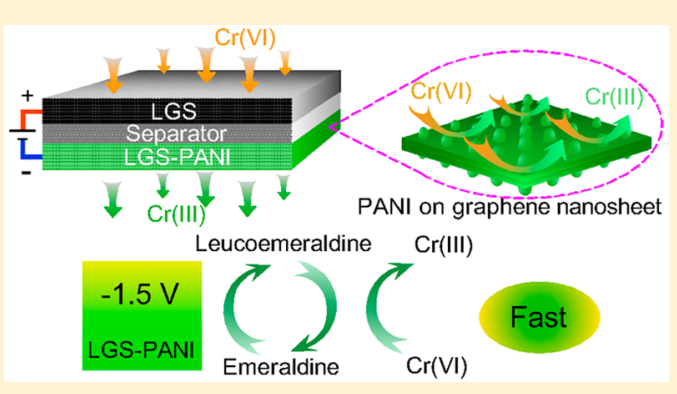
through mode greatly enhances the mass transfer and that the nanoscale convection induced by the PANI nanodots increases the nanoscale mass transport in the interfacial region of the electrode/ solution. In situ Raman spectroscopy shows that the PANI-Cr(VI) redox reactions are dominated by the leucoemeraldine/ emeraldine transition at $1.5 \mathrm{~V}$ cell voltage, which also remarkably contributes to the fast reaction kinetics. Using single-pass flowthrough mode, the LGS-PANI electrode reaches an average reduction efficiency of $99.8 \%$ with residual Cr(VI) concentration of $22.3 \mathrm{ppb}$ (initial $[\mathrm{Cr}(\mathrm{VI})]=10 \mathrm{ppm}$, flux $=20 \mathrm{~L} \mathrm{~h}^{-1} \mathrm{~m}^{-2}$ ). A long-term stability test shows that the LGS-PANI maintains stable performance over 40 days of operation and achieves $>98 \%$ reduction efficiency, with average current efficiency of as high as 99.1\% (initial $[\mathrm{Cr}(\mathrm{VI})]=10 \mathrm{ppm}$, flux $=50 \mathrm{~L} \mathrm{~h}^{-1} \mathrm{~m}^{-2}$ ).
\end{abstract}

\section{INTRODUCTION}

The presence of chromium $(\mathrm{Cr})$ in the aquatic environment has been a serious threat to human health and ecosystems because of its high toxicity and nondegradability. ${ }^{1}$ Owing to its harmful effects on human health, hexavalent chromium $[\mathrm{Cr}(\mathrm{VI})]$ has been classified as a group 1 carcinogen by the International Agency for Research on Cancer. ${ }^{2}$ The release of $\mathrm{Cr}(\mathrm{VI})$ species into aquatic environments is mainly through industrial discharge from leather tanning, electronic device manufacturing, chrome plating, and other industrial activities. ${ }^{3}$ $\mathrm{Cr}(\mathrm{III})$ is less toxic and can be easily precipitated or adsorbed on various adsorbents. ${ }^{4}$ Therefore, the reduction of $\mathrm{Cr}(\mathrm{VI})$ to $\mathrm{Cr}(\mathrm{III})$ is considered to be a promising strategy for detoxification of $\mathrm{Cr}(\mathrm{VI}) .^{5-7}$

Current approaches for the reduction of $\mathrm{Cr}(\mathrm{VI})$ include chemical reduction, photocatalytic reduction, bioreduction, and electroreduction. ${ }^{8-11}$ Electroreduction demonstrates high efficiency, easy operation, and environmental compatibility, which could be especially useful for practical application. ${ }^{12,13}$ However, since the reduction reaction occurs at the cathode/ solution interface, electrostatic repulsion will hinder $\mathrm{Cr}(\mathrm{VI})$ species from migrating to the active sites on the cathode. On the other hand, the product [mostly $\mathrm{Cr}(\mathrm{III})$ species] will probably inhibit the further reduction reaction unless it is transferred to the bulk solution. ${ }^{14,15}$ Therefore, mass transfer is considered to play a critical role in the electroreduction of $\mathrm{Cr}(\mathrm{VI}) .{ }^{16,17}$ Unfortunately, the classical parallel-plate electrodes often show poor mass transfer. ${ }^{13}$ In such cases, the detoxification of aqueous $\mathrm{Cr}(\mathrm{VI})$, particularly when $\mathrm{Cr}(\mathrm{VI})$ is present at low concentration, often shows low current efficiency and results in high energy demand. ${ }^{17}$

Flow-through porous electrodes demonstrate high current efficiency, enhanced mass transfer, and high volumetric rates of reaction and have been used in fuel cells, ${ }^{18}$ electrooxidation, ${ }^{19}$ desalination, ${ }^{20}$ and adsorption. ${ }^{21}$ This flow-through architecture enables optimal utilization of the active sites inside the porous electrodes and provides enhanced rates of mass transport, which could be especially useful for treatment of dilute solutions. ${ }^{22}$ In theory, flow-through electrodes with continuous and nanostructured active materials supported on a porous architecture can facilitate mass transport and active materials

Received: July 8, 2015

Revised: September 22, 2015

Accepted: October 27, 2015

Published: October 27, 2015 
utilization. As one of the most-promising porous framework materials, the three-dimensional (3D) graphene-based framework with large surface area and interconnected macropores enables it to be an ideal support for nanomaterials. ${ }^{23,24}$

Due to its environmental stability and multiple intrinsic redox states associated with its good conductivity, polyaniline (PANI) has attracted a great deal of attention in the electrocatalytic reduction of $\mathrm{Cr}(\mathrm{VI}) .^{25-30}$ Nanostructured PANI (e. g., nanowires, nanodots, and films) shows improved performance because it increases the material usage and surface area. $^{31,32}$ A previous study showed that graphene-supported PANI exhibits superior electrochemical activities toward Cr(VI) reduction due to the abundant active sites and effective electron transfer. ${ }^{33}$ Here, we present a novel flow-through electrode of PANI supported on a lamellar-structured-graphene nanosheet hydrogel (LGS) (LGS-PANI) (Scheme 1). This flow-through

Scheme 1. Schematic Representation of the LGS-PANI Flow-through Electrode for Electrocatalytic Reduction of Cr(VI)

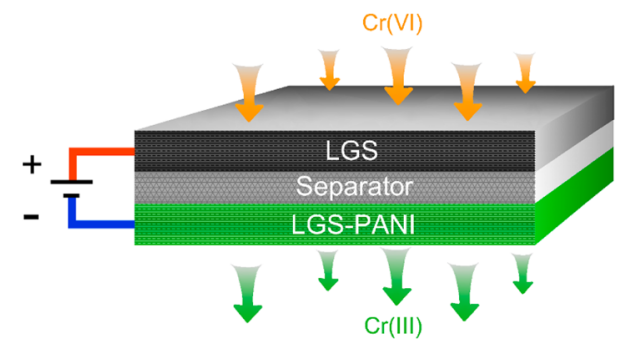

electrode demonstrates fast reaction kinetics for electrocatalytic reduction of $\mathrm{Cr}(\mathrm{VI})$, which enables it to achieve high reduction efficiency, even in single-pass mode. Computational fluid dynamics (CFD) simulation and in situ Raman spectroscopy were performed to gain insights into the mechanism of $\mathrm{Cr}(\mathrm{VI})$ reduction by the electrode.

\section{EXPERIMENTAL SECTION}

Materials Synthesis. Graphene oxide (GO) was synthesized from synthetic graphite powder $(<20 \mu \mathrm{m}$, Sigma-Aldrich) according to the modified Hummer's method. ${ }^{34}$ GO was dispersed in deionized water to form a $1.5 \mathrm{mg} \mathrm{mL}^{-1}$ dispersion. The graphene nanosheet hydrogel was obtained by hydrothermal reduction of GO. ${ }^{35}$ Typically, the GO dispersion (30 $\mathrm{mL}$ ) was sealed in a $50 \mathrm{~mL}$ Teflon-lined autoclave and maintained at $180{ }^{\circ} \mathrm{C}$ for $12 \mathrm{~h}$. After the autoclave cooled to room temperature, the as-prepared graphene nanosheet hydrogel was taken out and washed with deionized water. The LGS was prepared by direct compression of the graphene nanosheet hydrogel to form a $25 \times 25 \mathrm{~mm}^{2}$ electrode $(30 \mathrm{mg})$. The LGS-PANI was obtained by electrodeposition of aniline monomer on the LGS electrode [details of the procedure can be found in the Supporting Information (SI)]. The LGS-PANI electrode has an areal mass of $10 \mathrm{mg} \mathrm{cm}^{-2}$ and $\sim 400 \mu \mathrm{m}$ of total thickness.

Fabrication of the Flow-through Test Cell. As illustrated in Figure S1 (SI), two electrodes were separated by a porous dielectric membrane (pore size $0.8 \mu \mathrm{m}$ ) and encapsulated in a fixture of two acrylic glass plates. The anode (LGS electrode) and the cathode (LGS-PANI or LGS electrode) were supported with current collectors ( $\mathrm{Pt}$ mesh). The influent was injected into the anodic end of the cell and moved perpendicularly through the porous electrodes and finally out of the cell. The electrodes were connected to an electrochemical workstation (Interface1000, Gamry Instruments).

Kinetics Study Experiments. Three types of reactor systems were employed to study the kinetics of the $\mathrm{Cr}(\mathrm{VI})$ reduction. The three reaction systems were immersed sandwich-type (the cathode and anode sandwich a $\sim 50-\mu \mathrm{m}$ thick dielectric separator and were immersed in the solution), immersed parallel-plate (the cathode and anode with an interelectrode spacing of $1 \mathrm{~cm}$ were immersed in the solution), and sandwich-type flow-through modes. In all reaction systems, the LGS $\left(25 \times 25 \mathrm{~mm}^{2}, 30 \mathrm{mg}\right)$ and LGS-PANI $(25 \times 25$ $\mathrm{mm}^{2}, 65 \mathrm{mg}$ ) were employed as anode and cathode, respectively. A $100 \mathrm{~mL}$ portion of $20 \mathrm{ppm} \mathrm{Cr}(\mathrm{VI})$ solution with initial $\mathrm{pH}=2.0$ (or 5.0) was placed in a beaker. For immersed modes, the electrodes (sandwich-type or parallelplate) were totally immersed in the solution with stirring. For the flow-through mode, the $\mathrm{Cr}(\mathrm{VI})$ solution was pumped and injected through the flow-through cell by a peristaltic pump at a flow rate of $500 \mathrm{~L} \mathrm{~h}^{-1} \mathrm{~m}^{-2}$ with the effluent returned to the feed solution. The cell voltage was $1.5 \mathrm{~V}$ for each experiment.

Single-Pass Flow-through Experiments. A peristaltic pump was employed to pump $\mathrm{Cr}(\mathrm{VI})$ solution to the flowthrough test cell (Figure S2, SI). The effluents were collected by an automatic fraction collector at regular intervals. All the reduction experiments were carried out with the electrochemical workstation using the potentiostatic method.

The current efficiency (CE) was calculated by

$$
\mathrm{CE}=\frac{n F Q\left(C_{\mathrm{i}}-C_{\mathrm{e}}\right)}{M I}
$$

where $n$ is the number of electrons used in the electrochemical reaction $(n=3), F$ is the Faraday constant $\left(96485.3 \mathrm{C} \mathrm{mol}^{-1}\right)$, $I$ is the current $(\mathrm{A}), C_{\mathrm{i}}$ is the $\mathrm{Cr}(\mathrm{VI})$ concentration in the influent $(\mathrm{g} / \mathrm{L}), C_{\mathrm{e}}$ is the $\mathrm{Cr}(\mathrm{VI})$ concentration in the effluent $(\mathrm{g} / \mathrm{L}), Q$ is the flow rate $(\mathrm{L} / \mathrm{s})$, and $M$ is the molar mass of $\mathrm{Cr}$ $\left(52 \mathrm{~g} \mathrm{~mol}^{-1}\right)$.

Characterization. The as-prepared LGS and LGS-PANI were characterized by X-ray photoelectron spectroscopy (XPS, ESCALAB 250Xi, Thermo Scientific), X-ray powder diffraction (XRD, X’Pert PRO, PANalytical Co.), field-emission scanning electron microscopy (SEM, SU8020, Hitachi), and confocal raman microscopy (inVia-Reflex, Renishaw). The electron paramagnetic resonance (EPR) was measured using a Bruker A300 10/12 spectrometer. Total $\mathrm{Cr}$ concentrations were measured by inductively coupled plasma optical emission spectrometry (ICP-OES, 710, Agilent Technologies). The concentration of $\mathrm{Cr}(\mathrm{VI})$ in solution was analyzed on the basis of the conventional 1,5-diphenylcarbazide spectrophotometric methods according to the standard methods for the examination of water and wastewater, using a UV-vis spectrophotometer (U-3010, Hitachi) at $540 \mathrm{~nm} .{ }^{36}$ Assuming that the reduction product of $\mathrm{Cr}(\mathrm{VI})$ is $\mathrm{Cr}(\mathrm{III})$, the concentration of $\mathrm{Cr}$ (III) was calculated according to the following equation

$$
C_{\mathrm{Cr}(\mathrm{III})}=C_{\mathrm{t}}-C_{\mathrm{Cr}(\mathrm{VI})}
$$

where $C_{t}$ is the total concentration of $\mathrm{Cr}$ and $C_{\mathrm{Cr}(\mathrm{VI})}$ is the concentration of $\mathrm{Cr}(\mathrm{VI})$. 


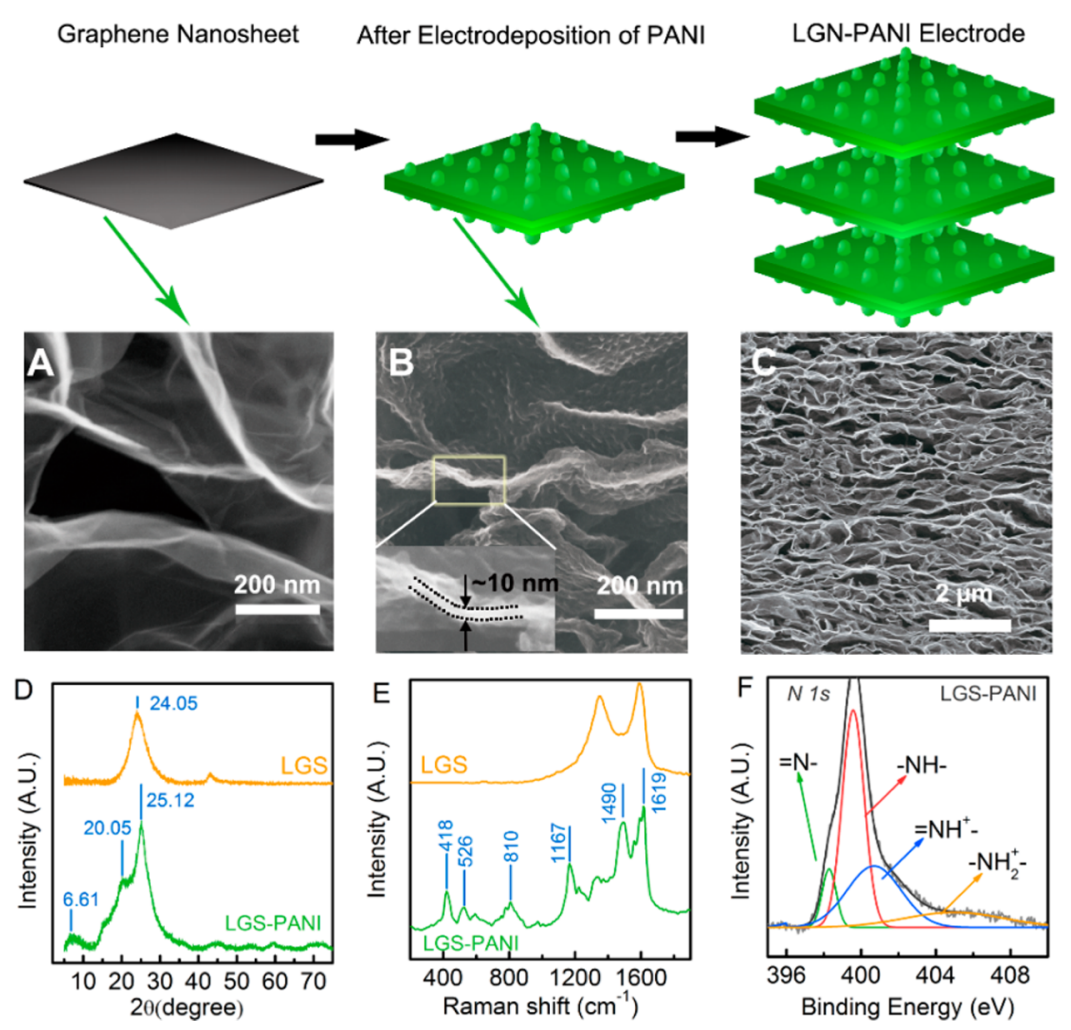

Figure 1. Schematic illustration of the fabrication process and characterization of the LGS-PANI electrode. SEM images of (A) graphene nanosheet substrate, (B) after electrodeposition of PANI, and (C) LGS-PANI. (D) XRD patterns of the LGS and LGS-PANI. (E) Raman spectra of the LGS and LGS-PANI. (F) The XPS N 1s spectrum of LGS-PANI.

\section{RESULTS AND DISCUSSION}

Characterization of the LGS-PANI. The LGS-PANI was obtained by electrodeposition of aniline on the LGS substrate (Figure 1). The SEM image indicates that the macroporous LGS substrate provides a continuously interconnected 3D framework for electrodepostion of PANI (Figure 1A). Electrochemical polymerization of aniline monomer on the LGS substrate resulted in LGS-PANI. As shown in Figure 1B, the LGS-PANI inherited the open, wrinkled, and curved structure of the LGS. The hierarchically porous composite composed of $2 \mathrm{D}$ sheets has a rough surface with PANI nanodots (diameter of $\sim 15 \mathrm{~nm}$ ) homogeneously distributed across the sheets, which can increase the surface area of the composite. In addition, the magnified SEM image (Figure 1B inset) shows that the LGS-PANI has a thickness of $\sim 10 \mathrm{~nm}$. These characteristics are useful to provide fast ion diffusion channels and more accessible surface area for catalytic reactions. As can be seen from the SEM cross-sectional view, the LGS-PANI electrode shows an interlamellar spacing of hundreds of nanometers (Figure 1C).

In the XRD pattern, the strong diffraction peak of LGS at $2 \theta$ $=24.05^{\circ}$ is ascribed to the stacking of graphene layers. ${ }^{37}$ The three diffraction peaks of the LGS-PANI at $2 \theta=6.6^{\circ}, 20.05^{\circ}$, and $25.12^{\circ}$ are characteristic of PANI (Figure 1D)..$^{38}$ In the Raman spectrum of the LGS-PANI, several new bands (e.g., 418,526 , and $810 \mathrm{~cm}^{-1}$ ) are observed, attributed to emeraldine salt form of PANI (Figure 1E). ${ }^{39}$ These results confirm the successful deposition of PANI. The elemental characterization shows that the nitrogen content of the LGS-PANI was $9.01 \%$ (see XPS in Figure S3, SI). The XPS N 1s spectrum shows that the nitrogen atoms of the LGS-PANI were in the forms of $-\mathrm{N}=,-\mathrm{NH}-,-\mathrm{NH}^{+}=$, and $-\mathrm{NH}_{2}{ }^{+}-($Figure $1 \mathrm{~F}){ }^{40,41}$
Kinetics Study. In acidic solutions ( $\mathrm{pH}$ range 1.0-5.0), the electrocatalytic reduction of $\mathrm{Cr}(\mathrm{VI})$ at the LGS-PANI electrode can be described by eqs 2 and 3:

$$
\begin{aligned}
& 2 \mathrm{HCrO}_{4}^{-}(\mathrm{aq})+14 \mathrm{H}^{+}+3 \mathrm{PANI}^{0}(\mathrm{~s}) \\
& \rightarrow 2 \mathrm{Cr}^{3+}(\mathrm{aq})+3 \mathrm{PANI}^{2+}(\mathrm{s})+8 \mathrm{H}_{2} \mathrm{O} \\
& \mathrm{PANI}^{2+}(\mathrm{s}) \rightarrow \operatorname{PANI}^{0}(\mathrm{~s}) \\
& 2 \mathrm{HCrO}_{4}^{-}(\mathrm{aq})+14 \mathrm{H}^{+}+3 \mathrm{PANI}^{2+}(\mathrm{s}) \\
& \quad \rightarrow 2 \mathrm{Cr}^{3+}(\mathrm{aq})+3 \mathrm{PANI}^{4+}(\mathrm{s})+8 \mathrm{H}_{2} \mathrm{O} \\
& \mathrm{PANI}^{4+}(\mathrm{s}) \rightarrow \mathrm{PANI}^{2+}(\mathrm{s})
\end{aligned}
$$

where $\mathrm{PANI}^{0}, \mathrm{PANI}^{2+}$, and $\mathrm{PANI}^{4+}$ represent the leucoemeraldine, emeraldine, and pernigraniline form of PANI. ${ }^{25}$ Considering that the redox potential of $\mathrm{Cr}(\mathrm{VI}) / \mathrm{Cr}(\mathrm{III})\left(E^{\theta}=\right.$ $1.350 \mathrm{~V}$ vs NHE) is higher than that of $\mathrm{H}_{2} \mathrm{O} / \mathrm{O}_{2}\left(E^{\theta}=1.229 \mathrm{~V}\right.$ vs NHE), the anodic reaction will be the oxidation of $\mathrm{H}_{2} \mathrm{O}$ to $\mathrm{O}_{2}$.

The representative kinetic plots of different reaction system are shown in Figure 2A. The electrocatalytic reduction of $\mathrm{Cr}(\mathrm{VI})$ in all reaction systems obeyed pseudo-first-order kinetics during the 30 min reaction periods in acidic condition (initial $\mathrm{pH}=2.0$ ). In immersed modes, the sandwich-type electrode system shows a lower rate constant value $(k=0.011$ $\left.\min ^{-1}\right)$ than the parallel-plate system $\left(k=0.017 \mathrm{~min}^{-1}\right)$, which indicates that the sandwich-type system tends to hinder the reduction reactions. Nevertheless, the rate constant for the sandwich-type flow-through mode was $0.108 \mathrm{~min}^{-1}$, which was 6.4 times higher than the immersed parallel-plate mode and 9.8 times higher than the immersed sandwich-type mode. The 

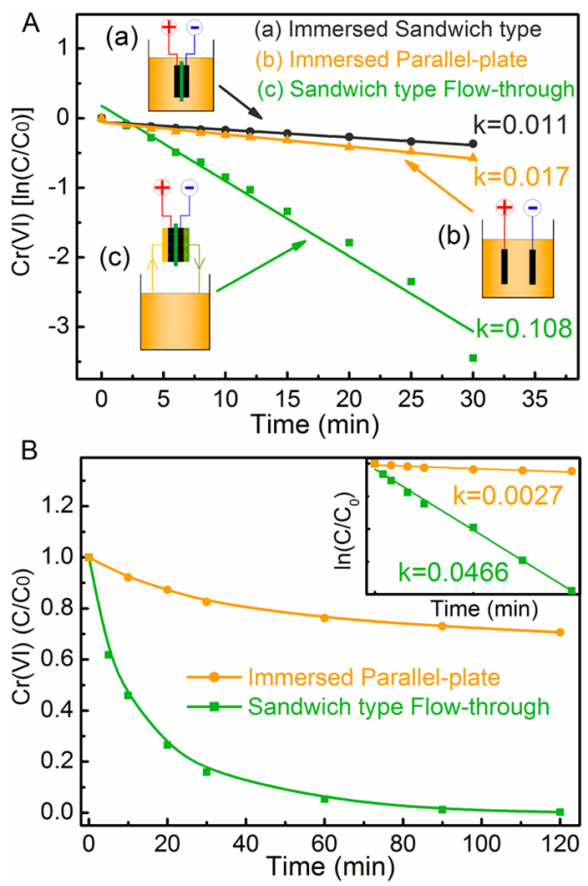

Figure 2. Kinetics investigation of the LGS-PANI electrode for the reduction of $\mathrm{Cr}(\mathrm{VI})$ in different reactor systems. (A) The electrocatalytic reduction of $\mathrm{Cr}(\mathrm{VI})$ at initial $\mathrm{pH}=2.0$. Reactor systems: (a) immersed sandwich-type mode, (b) immersed parallel-plate mode, and (c) sandwich-type flow-through mode. (B) Electrocatalytic reduction of $\mathrm{Cr}(\mathrm{VI})$ at initial $\mathrm{pH}=5.0$ (initial $[\mathrm{Cr}(\mathrm{VI})]=20 \mathrm{ppm}$, flow-through flux $=500 \mathrm{~L} \mathrm{~h}^{-1} \mathrm{~m}^{-2}$ ).

flow-through operation offers an opportunity to optimize the electroactive surface for catalytic reduction of $\mathrm{Cr}(\mathrm{VI})$ and to enable $\mathrm{Cr}(\mathrm{VI})$ to be directly carried to active sites in the LGSPANI by bulk flow, eliminating the long diffusion time required with immersed modes.

In neutral to alkaline solutions, the precipitation of $\mathrm{Cr}^{3+}$ takes place due to the formation of insoluble chromic hydroxides or $\mathrm{Cr}(\mathrm{III})$ hydroxide cation, as described in eq 4 :

$$
\mathrm{Cr}^{3+}(\mathrm{aq})+3 \mathrm{OH}^{-}(\mathrm{aq}) \rightarrow \mathrm{Cr}(\mathrm{OH})_{3}(\mathrm{~s})
$$

Even though the $\mathrm{pH}$ value in bulk solution is low, the local $\mathrm{pH}$ in the interfacial region of the cathode/solution may be quite high, especially when the applied potential is high enough as to promote the production of $\mathrm{OH}^{-}$, which will result in the formation of an insoluble chromic hydroxide layer on the electrode surface and hamper electron and mass transfer. ${ }^{14,42,43}$ As a result, further $\mathrm{Cr}(\mathrm{VI})$ reduction will be inhibited. Moreover, with increasing solution $\mathrm{pH}$, the redox potential of $\mathrm{Cr}$ (VI) species will sharply decrease, which will challenge the reducing ability of the electrode. ${ }^{42}$ For these reasons, the typical immersed parallel-plate electrode shows poor performance at neutral to alkaline conditions.

Figure 2B shows the reduction kinetics using the LGS-PANI electrode at initial $\mathrm{pH}=5.0$. Only $29.4 \%$ of $\mathrm{Cr}(\mathrm{VI})$ reduction is achieved after $120 \mathrm{~min}$ reaction in the immersed parallel-plate mode. In contrast, the sandwich-type flow-through mode shows that $99.9 \%$ of $\mathrm{Cr}(\mathrm{VI})$ is reduced in $120 \mathrm{~min}$. The pseudo-firstorder kinetics study demonstrates that the rate constant of the sandwich-type flow-through mode $(k=0.0466)$ is 17.3 times higher than that of the immersed parallel-plate mode $(k=$ 0.0027) (Figure 2B inset). The reduction of $\mathrm{Cr}(\mathrm{VI})$ using single-pass flow-through mode shows that more than $93 \%$ total $\mathrm{Cr}$ is in the effluent, which means that only small amount of $\mathrm{Cr}$ [Cr(VI) or $\mathrm{Cr}(\mathrm{III})$ species] is retained in the LGS-PANI electrode and the insoluble $\mathrm{Cr}$ (III) species can be driven out of the porous framework by the microfluidic flow (Figure S4, SI). This performance makes the LGS-PANI flow-through electrode more appropriate for the reduction of $\mathrm{Cr}(\mathrm{VI})$ over a broader $\mathrm{pH}$ range.

Single-Pass Flow-through Operation. The performance of the LGS and LGS-PANI electrodes using single-pass operation is shown in Figure 3. Owing to the high efficiency of
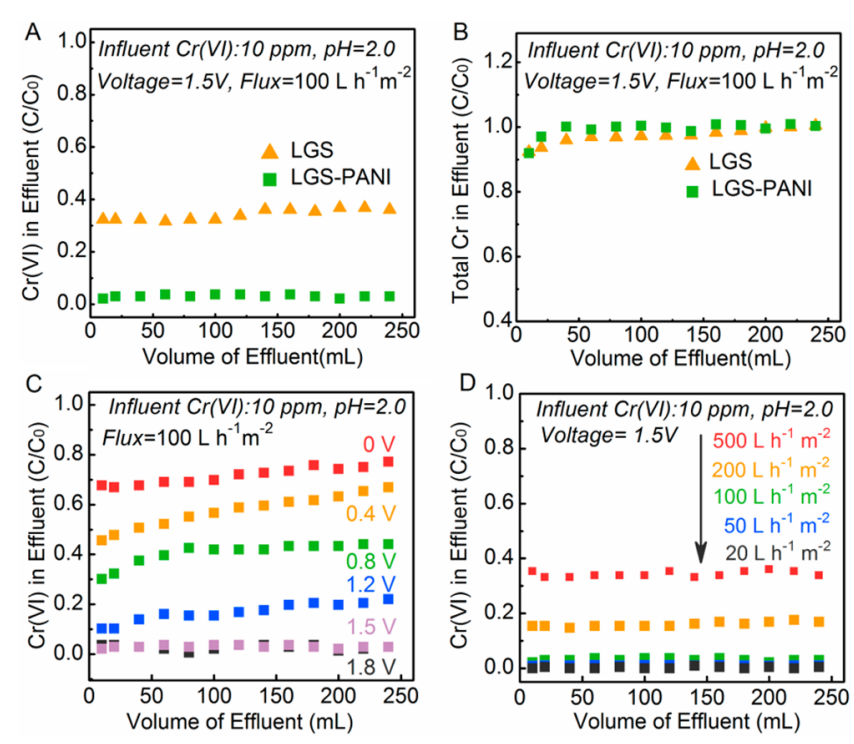

Figure 3. Single-pass flow-through mode for reduction of $\mathrm{Cr}(\mathrm{VI})$ using LGS and LGS-PANI electrodes. The influence of electrode material on the reduction of $\mathrm{Cr}(\mathrm{VI})$ (A) and total $\mathrm{Cr}$ (B) in the effluent. The influence of cell voltage (C) and flux (D) on the reduction of $\mathrm{Cr}(\mathrm{VI})$ using LGS-PANI.

the flow-through electrode, even the LGS (without PANI) shows $\sim 70 \%$ reduction of total $\mathrm{Cr}(\mathrm{VI})$ at a cell voltage of $1.5 \mathrm{~V}$ using single-pass operation (Figure 3A). However, 98\% $\mathrm{Cr}(\mathrm{VI})$ reduction is observed for the LGS-PANI flow-through electrode, demonstrating the strong activity of LGS-PANI in electrocatalytic reduction of $\mathrm{Cr}(\mathrm{VI})$. The total $\mathrm{Cr}$ in the effluent remains the same as that in the influent, except for a slight decrease in the samples collected at the beginning of the test, which suggests that there is only a little adsorption of $\mathrm{Cr}$ species on the electrodes (Figure 3B). Considering that adsorption will possibly inhibit the reduction reaction by reducing the activity of the PANI, this performance demonstrates the great advantage of the LGS-PANI flowthrough electrode, the possibility to achieve long-term continuous operation with high activity.

To determine the critical voltage for operating the LGSPANI flow-through electrode system, the influence of cell voltage on the reduction of $\mathrm{Cr}(\mathrm{VI})$ was studied (Figure 3C). At cell voltages lower than $1.5 \mathrm{~V}$, a decrease of reduction efficiency was observed with increasing effluent volume; for example, at the cell voltage of $0.4 \mathrm{~V}$, the reduction efficiency of $\mathrm{Cr}(\mathrm{VI})$ was $\sim 55 \%$ at the beginning and decreased to $\sim 33 \%$ after $240 \mathrm{~g}$ of $\mathrm{Cr}(\mathrm{VI})$ solution was treated. This is attributed to the multiple intrinsic redox states of PANI, which enable it to reduce the $\mathrm{Cr}(\mathrm{VI})$ even at low voltages (or at open circuit), accompanied by the transformation of PANI from the emeraldine to 
pernigraniline form (the highest oxidation state). ${ }^{44}$ This transformation results in the loss of reduction ability of PANI, leading to a decrease in $\mathrm{Cr}(\mathrm{VI})$ reduction efficiency. However, the LGS-PANI achieves the highest reduction efficiency $(\sim 98 \%)$ and retains its high reducing activity at the cell voltage of $1.5 \mathrm{~V}$, reflecting the establishment of an equilibrium between the oxidation and reduction of PANI.

The effect of the flux on the $\mathrm{Cr}(\mathrm{VI})$ reduction was investigated (Figure 3D). Since the reduction reactions take place at the surface of the PANI, the contact time (which is inversely proportional to the flux) in single-pass mode is very short. Therefore, higher fluxes often lead to lower reduction efficiencies. Nevertheless, a reduction efficiency of up to $\sim 85 \%$ and $\sim 65 \%$ was achieved at flux values as high as 200 and $500 \mathrm{~L}$ $\mathrm{h}^{-1} \mathrm{~m}^{-2}$, respectively. Conversely, when the flux decreased to $20 \mathrm{~L} \mathrm{~h}^{-1} \mathrm{~m}^{-2}$, an average reduction efficiency of $99.8 \%$ with $22.3 \mathrm{ppb}$ of residual $\mathrm{Cr}(\mathrm{VI})$ can be reached. However, there must be a trade-off between the reduction efficiency and the flux once it is put into practical application.

Mechanism Study. CFD simulation was carried out to visualize the velocity field in the lamellar microchannels (Figure 4). Since truly simulating the microfluidic flow in the LGSPANI would be exceedingly difficult, we neglected the weak chemical reaction in such a dilute solution and chose to visualize the flow field in a porous network consisting of a series of slit-shaped pores, which represented the microchannel in the LGS-PANI. The microscale velocity field of water in flowthrough mode was simulated and compared to that of immersed (flow-by) mode to determine if mass transport was enhanced. As shown in Figure 4A, the velocity magnitude contour in flow-through mode demonstrates that the microfluidic flow homogeneously distributes in the interspace of the LGS-PANI. This distribution of flow field enables optimal utilization of the PANI in the porous electrodes. $\mathrm{Cr}(\mathrm{VI})$ species could be driven to the surface of the LGS-PANI by microfluidic flow, which could greatly enhance the mobility of reactants and subsequently improve the reaction efficiency. ${ }^{45}$ In contrast, the immersed mode shows almost no liquid flowing into the interspace of the LGS-PANI, implying that the reduction of $\mathrm{Cr}(\mathrm{VI})$ largely takes place at the surface of the bulk electrode (Figure 4B).

As the behavior of the fluid is greatly influenced by the geometry of the flow channel, ${ }^{46}$ we studied the impact of the LGS-PANI surface on the velocity field. The SEM images show that the PANI nanodots are uniformly distributed across the surface of the LGS-PANI (Figure 4C). The nanoscale velocity vector field demonstrates that the nanoscale convection induced by the PANI nanodots causes enhanced mixing and hence increases the nanoscale mass transfer. In contrast, no nanoscale convection was observed near the surface of the LGS (Figure 4D). The nanoscale investigation of the flow clearly demonstrates that the PANI nanodots play a crucial role in the mass transport at the interfacial region of the LGS-PANI. These findings provide further evidence for the fast reduction kinetics.

In situ Raman spectroscopy was performed to study the transitions of PANI at different cell voltages in $\mathrm{H}_{2} \mathrm{SO}_{4}$ and $\mathrm{H}_{2} \mathrm{CrO}_{4}$ electrolytes (Figure $5 \mathrm{~A}$ ). In $\mathrm{H}_{2} \mathrm{SO}_{4}$ electrolyte, the fully oxidized form (pernigraniline form) of the PANI shows typical bands located at 1160,1254 , and $1514 \mathrm{~cm}^{-1}$, assigned to $\mathrm{C}-\mathrm{H}$ bending of the quinoid ring, $\mathrm{C}-\mathrm{N}$ stretching of the quinoid ring, and $\mathrm{C}=\mathrm{N}$ stretching of the quinoid ring, respectively. ${ }^{47,48}$ The decrease of the cell voltage (+0.4 to

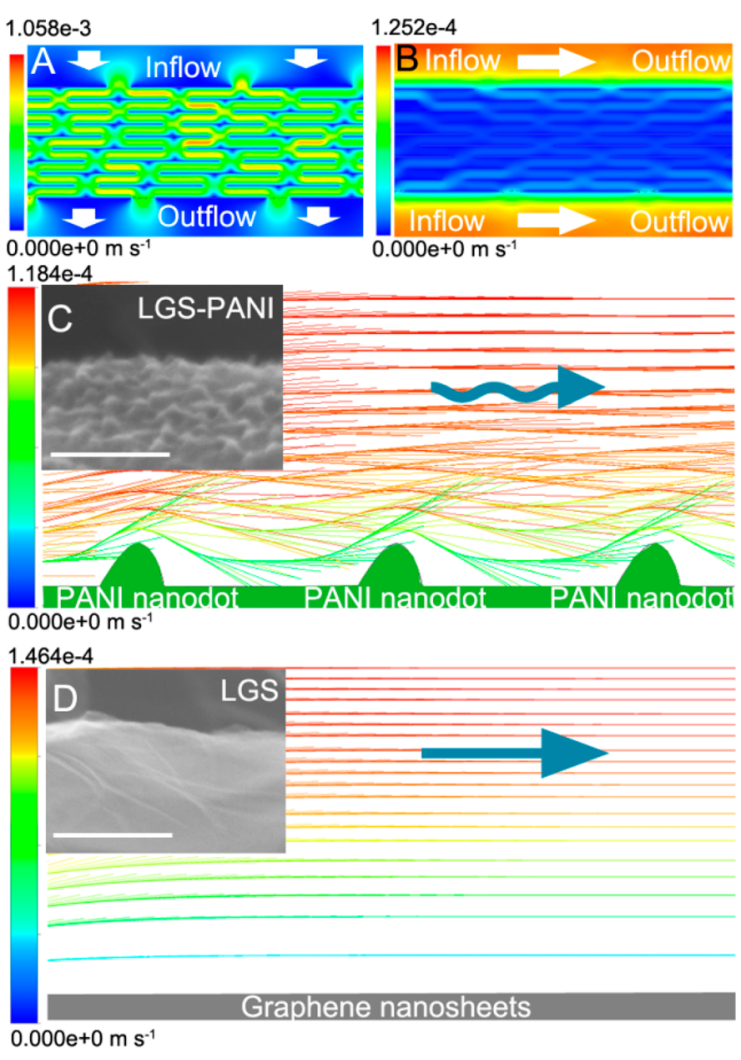

Figure 4. Views of the flow behaviors in the LGS and LGS-PANI obtained from CFD calculations. (A) The velocity magnitude contour of water flow through the LGS-PANI electrode (flow-through mode). (B) The velocity magnitude contour of water flow by the LGS-PANI electrode (immersed mode). The contours visualize the water flow in 10 layers of LGS-PANI sheets with interspaces of $500 \mathrm{~nm}$. White arrows represent the flow direction. (C) The nanoscale velocity vector field in the microchannels of the LGS-PANI shows the influence of the PANI nanodots on the water flow. The PANI nanodots are $\sim 10$ $\mathrm{nm}$ in height and $\sim 15 \mathrm{~nm}$ in diameter. The inset shows the SEM image of the PANI nanodots on the LGS-PANI sheet. (D) The nanoscale velocity vector field in the microchannel of the LGS. The inset shows the SEM image of the graphene nanosheets of the LGS. Scale bar: $100 \mathrm{~nm}$. The details of the models used for CFD simulation are given in the Figures S5 and S6 (SI).

$-1.2 \mathrm{~V}$ ) results in the structure change of the PANI, resulting in changes in intensity of bands at 810,1186, 1420,1486, and $1590 \mathrm{~cm}^{-1}$, originally from amine deformation $(\mathrm{C}-\mathrm{N}-\mathrm{C}$ bending), $\mathrm{C}-\mathrm{H}$ bending, $\mathrm{C}-\mathrm{C}$ stretching, $\mathrm{C}=\mathrm{N}$ stretching, and $\mathrm{C}=\mathrm{C}$ stretching, respectively. ${ }^{49}$ The increase in the intensity of the band at $1186 \mathrm{~cm}^{-1}$ and decrease of the intensity of the band at $1160 \mathrm{~cm}^{-1}$ are due to the transition of quinoid to benzoid rings. All these changes reflect the transition of the PANI from the pernigraniline to emeraldine structure (partially oxidized state). At cell voltage of $-1.5 \mathrm{~V}$, two predominant bands at 1350 and $1610 \mathrm{~cm}^{-1}$ are characteristic of the fully reduced state of the PANI, associated with the change from emeraldine structure to leucoemeraldine structure. ${ }^{50}$ Thus, in brief, the transition of the PANI from the pernigraniline to leucoemeraldine structure is a continuous process that can be achieved by tuning the cell voltage (from $+1.5 \mathrm{~V}$ to $-1.5 \mathrm{~V}$ ).

Two types of transitions of the PANI are involved in the PANI-Cr(VI) redox reactions: leucoemeraldine/emeraldine and emeraldine/pernigraniline. As shown in Figure 5A, the PANI can be oxidized from the emeraldine to pernigraniline 

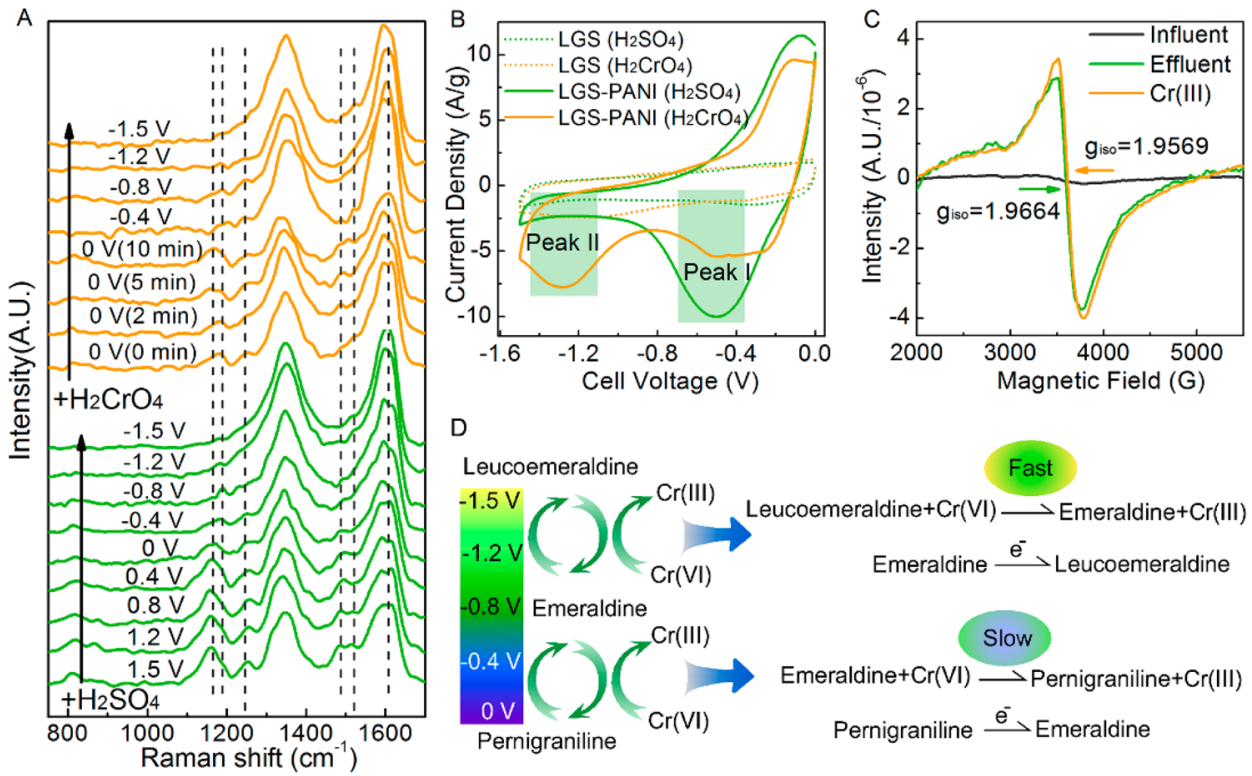

Figure 5. Mechanism study. (A) In situ Raman spectroscopy study shows the transitions of the PANI at various cell voltages (green lines). The in situ Raman spectra of the PANI in $0.5 \mathrm{M} \mathrm{H}_{2} \mathrm{SO}_{4}$ at applied cell voltages from $-1.5 \mathrm{~V}$ to $+1.5 \mathrm{~V}$ (orange lines). The in situ Raman spectra of the PANI in $0.1 \mathrm{M} \mathrm{H}_{2} \mathrm{CrO}_{4}$ at applied cell voltages from $0 \mathrm{~V}$ (open circuit, for $10 \mathrm{~min}$ ) to $-1.5 \mathrm{~V}$. The plus and minus signs represent the PANI as anode and cathode, respectively. (B) Cyclic voltammogram of LGS and LGS-PANI in $0.5 \mathrm{M} \mathrm{H}_{2} \mathrm{SO}_{4}$ and $0.1 \mathrm{M} \mathrm{H}_{2} \mathrm{CrO}_{4}$. Scan rate: $10 \mathrm{mV} / \mathrm{s}$. (C) Xband EPR spectra from solutions of the electrocatalytic reduction of $\mathrm{Cr}(\mathrm{VI})$ with LGS-PANI electrode. Influent: $\mathrm{pH}=2.0,[\mathrm{Cr}(\mathrm{VI})]=100 \mathrm{ppm}$. Spectrometer settings: microwave power $=53 \mathrm{~mW}$, receiver gain $=1.0 \times 10^{5}$, modulation amplitude $=5 \mathrm{G}$, time constant $=0.327 \mathrm{~s}$. (D) Proposed mechanism of the electrocatalytic reduction of $\mathrm{Cr}(\mathrm{VI})$ by the LGS-PANI electrode. The transition of the PANI among the pernigraniline, emeraldine, and leucoemeraldine structures is a continuous process. The scheme illustrates two typical cases to demonstrate the fast and slow kinetics involved in the catalytic reaction. The minus sign of the cell voltage represents that the PANI is the cathode.

structure at open circuit (from $0 \mathrm{~V} 0 \mathrm{~min}$ to $0 \mathrm{~V} 10 \mathrm{~min}$ ). Once the LGS-PANI electrode is negatively charged at cell voltages between -0.4 and $-1.2 \mathrm{~V}$, the PANI is converted to the emeraldine structure, which implies that the emeraldine/ pernigraniline transition dominates the $\mathrm{Cr}(\mathrm{VI})$ reduction at low cell voltages. However, when the cell voltage increases to $-1.5 \mathrm{~V}$, the PANI is further reduced to the leucoemeraldine form, suggesting that the $\mathrm{Cr}(\mathrm{VI})$ reduction probably accompanies the leucoemeraldine/emeraldine transition.

Typical electrochemical responses show that PANI can also greatly enhance the activity of the LGS in $\mathrm{Cr}(\mathrm{VI})$ reduction (Figure 5B). The LGS-PANI electrode shows a predominant peak (I) at $-0.5 \mathrm{~V}$ cell voltage in $\mathrm{H}_{2} \mathrm{SO}_{4}$ solution, which is due to the reduction of PANI, while in $\mathrm{H}_{2} \mathrm{CrO}_{4}$ solution, the peak (II) at $-1.3 \mathrm{~V}$ can be attributed to the reduction of $\mathrm{Cr}(\mathrm{VI})$. No obvious hydrogen evolution reaction occurred. This result is consistent with the in situ Raman study. The EPR spectrum acquired with $100 \mathrm{ppm} \mathrm{Cr}(\mathrm{III})$ solution $\left(\mathrm{pH}=2.0, \mathrm{CrCl}_{3}\right)$ shows a strong signal at $g_{\text {iso }}=1.9569$, which can be attributed to $\mathrm{Cr}$ (III) (Figure 5C). In the effluent, the same signal was also detected at $g_{\text {iso }}=1.9664$, confirming that the product of electrocatalytic reaction of $\mathrm{Cr}(\mathrm{VI})$ with LGS-PANI was Cr(III). ${ }^{51}$

On the basis of the above analysis, Figure 5D illustrates the proposed mechanism of the electrocatalytic reduction of $\mathrm{Cr}(\mathrm{VI})$. The content of "reduced units" in the PANI plays an important role in the catalytic reduction of $\mathrm{Cr}(\mathrm{VI}){ }^{25}$ As the fully reduced state of PANI, leucoemeraldine possesses the highest "reduced units" content. ${ }^{29}$ On the basis of this point, in the LGS-PANI flow-through electrode, tuning the reaction to make the PANI-Cr(VI) redox reactions dominated by the leucoemeraldine/emeraldine transition would be beneficial to the $\mathrm{Cr}(\mathrm{VI})$ reduction. Indeed, the reduction of $\mathrm{Cr}(\mathrm{VI})$ using single-pass flow-through mode achieved the highest reduction efficiency at $1.5 \mathrm{~V}$ cell voltage and confirmed the high catalytic activity of the leucoemeraldine/emeraldine transition.

Durability Performance. To evaluate the durability of the LGS-PANI flow-through electrode, a long-term stability test for electrocatalytic reduction of $\mathrm{Cr}(\mathrm{VI})$ was performed (Figure 6). After 40 days, the LGS-PANI flow-through electrode still reteained nearly $100 \%$ of its initial performance. The currenttime plot demonstrated stable current, and the average current efficiency was calculated to be $99.1 \%$. The variation of the current efficiency was attributed to the fluctuation of the residual $\mathrm{Cr}$ (VI) and the multiple redox states of PANI, as well as some mild side reactions. The cell after the 40-day test was

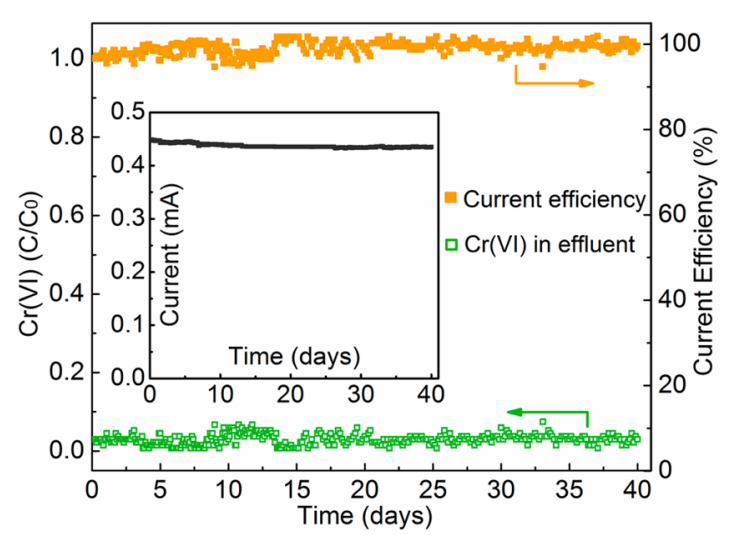

Figure 6. The durability performance of the LGS-PANI flow-through electrode. The inset shows the current-time plot in the 40-day durability test. Influent: $[\mathrm{Cr}(\mathrm{VI})]=10 \mathrm{ppm}, \mathrm{pH}=2.0$. flow-through flux $=50 \mathrm{~L} \mathrm{~h}^{-1} \mathrm{~m}^{-2}$, cell voltage $=1.5 \mathrm{~V}$. 
disassembled and the LGS-PANI was investigated by SEM and XPS (Figures S7 and S8, SI). Surprisingly, the SEM image shows that the frame structure of the LGS-PANI still maintained its original morphology. Furthermore, the XPS N 1s spectrum of the LGS-PANI demonstrates the negligible change of $\mathrm{N}$ species after the long-term stability test. This remarkable durability is ascribed to the low operation voltage, resulting in a mild reaction condition, which prevents the decomposition of the LGS or LGS-PANI electrodes. ${ }^{52}$ In addition, the open porous framework provides this flowthrough electrode with sufficient flow channels and low pressure drop, consequently preserving the framework structure.

This work demonstrates a novel electrocatalytic system based on the LGS-PANI flow-through electrode for aqueous $\mathrm{Cr}$ (VI) reduction. The results here emphasize the beneficial effects of the interconnected 3D network of graphene hydrogel and the high activity of the PANI in electrocatalytic reduction of $\mathrm{Cr}(\mathrm{VI})$, which enable the LGS-PANI flow-through electrode to achieve excellent performance even in single-pass mode. This flow-through architecture achieves full utilization of the lamellar-structured porous electrode and provides enhanced mass transport from the bulk solution to the active sites. In addition, the high energy efficiency obtained in long-time operation demonstrates that this system would be economically feasible in $\mathrm{Cr}(\mathrm{VI})$ detoxification. As the high efficiency is due to the enhanced mass transfer and optimized cell voltage, this mechanism may be of great significance, because it provides guidelines for design and development of electrochemical reactors for practical applications. This study suggests that tailor-made functional materials obtained by anchoring or impregnating a macroporous framework with nanomaterials could potentially be applied to treat various dilute solutions. Furthermore, the success of this strategy could open up new opportunities in developing high-performance electrode materials and electrochemical technologies for water decontamination.

\section{ASSOCIATED CONTENT}

\section{S Supporting Information}

The Supporting Information is available free of charge on the ACS Publications website at DOI: 10.1021/acs.est.5b03314.

The details of experiments, CFD simulation, and Figures S1-S8 (PDF)

\section{AUTHOR INFORMATION}

\section{Corresponding Author}

*E-mail: hjliu@rcees.ac.cn.

\section{Notes}

The authors declare no competing financial interest.

\section{ACKNOWLEDGMENTS}

This work was supported by the National Science Fund for Distinguished Young Scholars of China (Grant No. 51225805), Major Program of the National Natural Science Foundation of China (Grant No. 51438011), and General Program of the National Natural Science Foundation of China (Grant No. 51478455).

\section{REFERENCES}

(1) Fu, F.; Wang, Q. Removal of heavy metal ions from wastewaters: A review. J. Environ. Manage. 2011, 92, 407-418.
(2) IARC. Chromium and Certain Chromium Compounds; International Agency for Research on Cancer (IARC): Lyon, France, 1982.

(3) Owlad, M.; Aroua, M.; Daud, W.; Baroutian, S. Removal of Hexavalent Chromium-Contaminated Water and Wastewater: A Review. Water, Air, Soil Pollut. 2009, 200, 59-77.

(4) Ali, I. New Generation Adsorbents for Water Treatment. Chem. Rev. 2012, 112, 5073-5091.

(5) Qian, A.; Liao, P.; Yuan, S.; Luo, M. Efficient reduction of Cr(VI) in groundwater by a hybrid electro-Pd process. Water Res. 2014, 48, 326-334.

(6) Okello, V. A.; Mwilu, S.; Noah, N.; Zhou, A.; Chong, J.; Knipfing, M. T.; Doetschman, D.; Sadik, O. A. Reduction of Hexavalent Chromium Using Naturally-Derived Flavonoids. Environ. Sci. Technol. 2012, 46, 10743-10751.

(7) Shevchenko, N.; Zaitsev, V.; Walcarius, A. Bifunctionalized Mesoporous Silicas for $\mathrm{Cr}(\mathrm{VI})$ Reduction and Concomitant $\mathrm{Cr}$ (III) Immobilization. Environ. Sci. Technol. 2008, 42, 6922-6928.

(8) Wang, L.; Wang, N.; Zhu, L.; Yu, H.; Tang, H. Photocatalytic reduction of $\mathrm{Cr}(\mathrm{VI})$ over different $\mathrm{TiO} 2$ photocatalysts and the effects of dissolved organic species. J. Hazard. Mater. 2008, 152, 93-99.

(9) Lai, K. C. K.; Lo, I. M. C. Removal of Chromium (VI) by AcidWashed Zero-Valent Iron under Various Groundwater Geochemistry Conditions. Environ. Sci. Technol. 2008, 42, 1238-1244.

(10) Xafenias, N.; Zhang, Y.; Banks, C. J. Enhanced Performance of Hexavalent Chromium Reducing Cathodes in the Presence of Shewanella oneidensis MR-1 and Lactate. Environ. Sci. Technol. 2013, 47, 4512-4520.

(11) Rodríguez, F. J.; Gutiérrez, S.; Ibanez, J. G.; Bravo, J. L.; Batina, N. The Efficiency of Toxic Chromate Reduction by a Conducting Polymer (Polypyrrole): Influence of Electropolymerization Conditions. Environ. Sci. Technol. 2000, 34, 2018-2023.

(12) Zhang, Y.; Li, Q.; Tang, R.; Hu, Q.; Sun, L.; Zhai, J. Electrocatalytic reduction of chromium by poly(aniline-co-o-aminophenol): An efficient and recyclable way to remove $\mathrm{Cr}(\mathrm{VI})$ in wastewater. Appl. Catal., B 2009, 92, 351-356.

(13) Barrera-Díaz, C. E.; Lugo-Lugo, V.; Bilyeu, B. A review of chemical, electrochemical and biological methods for aqueous $\mathrm{Cr}(\mathrm{VI})$ reduction. J. Hazard. Mater. 2012, 223-224, 1-12.

(14) Rodriguez-Valadez, F.; Ortiz-Éxiga, C.; Ibanez, J. G.; AlatorreOrdaz, A.; Gutierrez-Granados, S. Electroreduction of $\mathrm{Cr}(\mathrm{VI})$ to $\mathrm{Cr}(\mathrm{III})$ on Reticulated Vitreous Carbon Electrodes in a Parallel-Plate Reactor with Recirculation. Environ. Sci. Technol. 2005, 39, 18751879.

(15) Roberts, E. P. L.; Yu, H. Chromium removal using a porous carbon felt cathode. J. Appl. Electrochem. 2002, 32, 1091-1099.

(16) Ruotolo, L. A. M.; Gubulin, J. C. Chromium(VI) reduction using conducting polymer films. React. Funct. Polym. 2005, 62, 141151.

(17) Radwan, A.; El-Kiar, A.; Farag, H. A.; Sedahmed, G. H. The role of mass transfer in the electrolytic reduction of hexavalent chromium at gas evolving rotating cylinder electrodes. J. Appl. Electrochem. 1992, 22, 1161-1166.

(18) Kjeang, E.; Michel, R.; Harrington, D. A.; Djilali, N.; Sinton, D. A Microfluidic Fuel Cell with Flow-Through Porous Electrodes. J. Am. Chem. Soc. 2008, 130, 4000-4006.

(19) Liu, H.; Vajpayee, A.; Vecitis, C. D. Bismuth-Doped Tin OxideCoated Carbon Nanotube Network: Improved Anode Stability and Efficiency for Flow-Through Organic Electrooxidation. ACS Appl. Mater. Interfaces 2013, 5, 10054-10066.

(20) Suss, M. E.; Baumann, T. F.; Bourcier, W. L.; Spadaccini, C. M.; Rose, K. A.; Santiago, J. G.; Stadermann, M. Capacitive desalination with flow-through electrodes. Energy Environ. Sci. 2012, 5, 9511-9519.

(21) Liu, H.; Zuo, K.; Vecitis, C. D. Titanium Dioxide-Coated Carbon Nanotube Network Filter for Rapid and Effective Arsenic Sorption. Environ. Sci. Technol. 2014, 48, 13871-13879.

(22) Newman, J.; Thomas-Alyea, K. E. Electrochemical Systems, 3rd ed.; John Wiley \& Sons, Inc.: Hoboken, NJ, 2004. 
(23) Shen, Y.; Fang, Q.; Chen, B. Environmental Applications of Three-Dimensional Graphene-Based Macrostructures: Adsorption, Transformation, and Detection. Environ. Sci. Technol. 2015, 49, 67-84.

(24) Tesh, S. J.; Scott, T. B. Nano-Composites for Water Remediation: A Review. Adv. Mater. 2014, 26, 6056-6068.

(25) Farrell, S. T.; Breslin, C. B. Reduction of $\mathrm{Cr}(\mathrm{VI})$ at a Polyaniline Film: Influence of Film Thickness and Oxidation State. Environ. Sci. Technol. 2004, 38, 4671-4676.

(26) Lakshmipathiraj, P.; Bhaskar Raju, G.; Raviatul Basariya, M.; Parvathy, S.; Prabhakar, S. Removal of Cr (VI) by electrochemical reduction. Sep. Purif. Technol. 2008, 60, 96-102.

(27) Kang, E. T.; Neoh, K. G.; Tan, K. L. Polyaniline: A polymer with many interesting intrinsic redox states. Prog. Polym. Sci. 1998, 23, 277324.

(28) Olad, A.; Nabavi, R. Application of polyaniline for the reduction of toxic $\mathrm{Cr}(\mathrm{VI})$ in water. J. Hazard. Mater. 2007, 147, 845-851.

(29) Huang, W.-S.; Humphrey, B. D.; MacDiarmid, A. G. Polyaniline, a novel conducting polymer. Morphology and chemistry of its oxidation and reduction in aqueous electrolytes. J. Chem. Soc., Faraday Trans. 1 1986, 82, 2385-2400.

(30) Ruotolo, L. A. M.; Gubulin, J. C. Reduction of hexavalent chromium using polyaniline films. Effect of film thickness, potential and flow velocity on the reaction rate and polymer stability. J. Appl. Electrochem. 2003, 33, 1217-1222.

(31) Wang, J.; Zhang, D. One-Dimensional Nanostructured Polyaniline: Syntheses, Morphology Controlling, Formation Mechanisms, New Features, and Applications. Adv. Polym. Technol. 2013, 32, E323-E368.

(32) Wang, Y.; Yang, X.; Qiu, L.; Li, D. Revisiting the capacitance of polyaniline by using graphene hydrogel films as a substrate: the importance of nano-architecturing. Energy Environ. Sci. 2013, 6, 477481.

(33) Yang, Y.; Diao, M.; Gao, M.; Sun, X.; Liu, X.; Zhang, G.; Qi, Z.; Wang, S. Facile Preparation of Graphene/Polyaniline Composite and Its Application for Electrocatalysis Hexavalent Chromium Reduction. Electrochim. Acta 2014, 132, 496-503.

(34) Kovtyukhova, N. I.; Ollivier, P. J.; Martin, B. R.; Mallouk, T. E.; Chizhik, S. A.; Buzaneva, E. V.; Gorchinskiy, A. D. Layer-by-Layer Assembly of Ultrathin Composite Films from Micron-Sized Graphite Oxide Sheets and Polycations. Chem. Mater. 1999, 11, 771-778.

(35) Xu, Y.; Sheng, K.; Li, C.; Shi, G. Self-Assembled Graphene Hydrogel via a One-Step Hydrothermal Process. ACS Nano 2010, 4, 4324-4330.

(36) APHA. Standard Methods for the Examination of Water and Wastewater, 20th ed.; Clescerl, L. S., Greenberg, A. E., Eaton, A. D., Eds.; American Public Health Association: Washington, DC, 1998.

(37) Vázquez-Santos, M. B.; Geissler, E.; László, K.; Rouzaud, J.-N.; Martínez-Alonso, A.; Tascón, J. M. D. Comparative XRD, Raman, and TEM Study on Graphitization of PBO-Derived Carbon Fibers. J. Phys. Chem. C 2012, 116, 257-268.

(38) Meng, Y.; Wang, K.; Zhang, Y.; Wei, Z. Hierarchical Porous Graphene/Polyaniline Composite Film with Superior Rate Performance for Flexible Supercapacitors. Adv. Mater. 2013, 25, 6985-6990.

(39) Cochet, M.; Louarn, G.; Quillard, S.; Buisson, J. P.; Lefrant, S. Theoretical and experimental vibrational study of emeraldine in salt form. Part II. J. Raman Spectrosc. 2000, 31, 1041-1049.

(40) Moulder, J. F.; Stickle, W. F.; Sobol, P. E.; Bomben, K. D. Handbook of X-ray Photoelectron Spectroscopy; Physical Electronics, Inc.: Eden Prairie, MN, 1995.

(41) Tong, Z.; Yang, Y.; Wang, J.; Zhao, J.; Su, B.; Li, Y. Layered polyaniline/graphene film from sandwich-structured polyaniline/ graphene/polyaniline nanosheets for high-performance pseudosupercapacitors. J. Mater. Chem. A 2014, 2, 4642-4651.

(42) Senthurchelvan, R.; Wang, Y.; Basak, S.; Rajeshwar, K. Reduction of Hexavalent Chromium in Aqueous Solutions by Polypyrrole: II. Thermodynamic, Kinetic, and Mechanistic Aspects. J. Electrochem. Soc. 1996, 143, 44-51.
(43) Lindbergh, G.; Simonsson, D. The Effect of Chromate Addition on Cathodic Reduction of Hypochlorite in Hydroxide and Chlorate Solutions. J. Electrochem. Soc. 1990, 137, 3094-3099.

(44) Guo, X.; Fei, G. T.; Su, H.; De Zhang, L. High-Performance and Reproducible Polyaniline Nanowire/Tubes for Removal of Cr(VI) in Aqueous Solution. J. Phys. Chem. C 2011, 115, 1608-1613.

(45) Wang, N.; Zhang, X.; Wang, Y.; Yu, W.; Chan, H. L. W. Microfluidic reactors for photocatalytic water purification. Lab Chip 2014, 14, 1074-1082.

(46) Kamyar, A.; Saidur, R.; Hasanuzzaman, M. Application of Computational Fluid Dynamics (CFD) for nanofluids. Int. J. Heat Mass Transfer 2012, 55, 4104-4115.

(47) Lindfors, T.; Kvarnström, C.; Ivaska, A. Raman and UV-vis spectroscopic study of polyaniline membranes containing a bulky cationic additive. J. Electroanal. Chem. 2002, 518, 131-138.

(48) Blacha-Grzechnik, A.; Turczyn, R.; Burek, M.; Zak, J. In situ Raman spectroscopic studies on potential-induced structural changes in polyaniline thin films synthesized via surface-initiated electropolymerization on covalently modified gold surface. Vib. Spectrosc. 2014, 71, 30-36.

(49) Berrada, K.; Quillard, S.; Louam, G.; Lefrant, S. Polyanilines and substituted polyanilines: a comparative study of the Raman spectra of leucoemeraldine, emeraldine and pernigraniline. Synth. Met. 1995, 69, 201-204.

(50) Arsov, L. D.; Plieth, W.; Koßmehl, G. Electrochemical and Raman spectroscopic study of polyaniline; influence of the potential on the degradation of polyaniline. J. Solid State Electrochem. 1998, 2, $355-361$.

(51) Omole, M. A.; Okello, V. A.; Lee, V.; Zhou, L.; Sadik, O. A.; Umbach, C.; Sammakia, B. Catalytic Reduction of Hexavalent Chromium Using Flexible Nanostructured Poly(amic acids). ACS Catal. 2011, 1, 139-146.

(52) Mažeikienè, R.; Niaura, G.; Malinauskas, A. Raman spectroelectrochemical study on the kinetics of electrochemical degradation of polyaniline. Polym. Degrad. Stab. 2008, 93, 1742-1746. 